\title{
Rehabilitation following total hip arthroplasty evaluation over short follow-up time: Randomized clinical trial
}

\author{
Carolina Sant’anna Umpierres, MSc; ${ }^{1-2}$ Tiango Aguiar Ribeiro, PhD; ${ }^{1-2}$ Ângela Elisabete Marchisio; ${ }^{1-2}$ Lívia \\ Galvão; ${ }^{1-2}$ Íngrid Nemitz Krás Borges; ${ }^{2}$ Carlos Alberto de Souza Macedo, PhD; ${ }^{2}$ Carlos Roberto Galia, PhD $^{1-2 *}$ \\ ${ }^{1}$ Postgraduate Program of Surgical Sciences, Faculty of Medical Sciences, Federal University of Rio Grande do Sul, Rio \\ Grande do Sul, Brazil; ${ }^{2}$ Department of Orthopedics, Hospital de Clínicas de Porto Alegre, Rio Grande do Sul, Brazil
}

\begin{abstract}
Hip osteoarthritis (OA) is a degenerative disease, and total hip arthroplasty (THA) is one of the surgical procedures of choice to improve the OA patient's quality of life. Without a rehabilitation program, THA patients will develop functional limitations. A randomized double-blind trial was performed between July 2009 and October 2011 to compare over a short follow-up time two groups of patients who underwent THA for OA. The THA protocol (THAP) group received verbal instructions and physiotherapy exercise demonstrations, and the THA physiotherapy care protocol (THAPCP) group received the same verbal instructions and demonstrations associated with daily exercise practice guided by a physiotherapist. The outcomes that were assessed preoperatively and $15 \mathrm{~d}$ postoperatively in 106 patients were muscle strength force, goniometry, Medical Outcomes Study 36-Item Short Form Health Survey, and Merle d'Aubigné and Postel score. Higher muscle strength force scores and degrees in range of motion were found in the THAPCP group. Greater improvements were also observed for the THAPCP group than the THAP group in the Merle d'Aubigné and Postel score. At the end of the follow-up period, the intervention in the THAPCP group improved functional capacity, quality of life, mobility, muscle strength, goniometry, and pain. It appears to be a safe tool for accelerating recovery in THA patients.
\end{abstract}

Clinical Trial Registration: ClinicalTrials.gov; NCT01491048, "Evaluation of functional rehabilitation in patients undergoing physiotherapy after total hip arthroplasty (arthrosis)";

https://clinicaltrials.gov/ct2/show/NCT01491048
Key words: activities of daily living, arthroplasty, hip osteoarthritis, Medical Outcomes Study 36-Item Short Form, musculoskeletal manipulations, osteoarthritis, physiotherapy, postoperative care, randomized controlled trial, total hip arthroplasty.

\section{INTRODUCTION}

Hip osteoarthrosis or osteoarthritis (OA) is a degenerative disease that affects the synovial joints. OA is considered the most common disease of the locomotor system [1-4] and is prevalent among middle-aged and elderly adults [5]. In these populations, a clear relationship between overweight and physical activities is observed [6-7]. Characterized by focal degeneration in joint cartilage, microfractures, cysts, subchondral bone sclerosis, and osteophyte formation in the articular borders, OA

\footnotetext{
Abbreviations: ADL $=$ activity of daily living, GLM $=$ generalized linear models, IQR = interquartile range, $\mathrm{OA}=$ osteoarthritis, SF-36 = Medical Outcomes Study 36-Item Short Form Health Survey, THA = total hip arthroplasty, THAP = total hip arthroplasty protocol, THAPCP = total hip arthroplasty physiotherapy care protocol.

*Address all correspondence to Carlos Roberto Galia, PhD; Hospital de Clínicas de Porto Alegre, Ramiro Barcelos 2350, CEP: 90035-003, Porto Alegre, Rio Grande do Sul, Brazil; +55-51-2101-8628. Email: cgalia@hcpa.ufrgs.br http://dx.doi.org/10.1682/JRRD.2014.05.0132
} 
leads to clinical signs of pain, stiffness, walking difficulty, deformity, and progressive loss of movements in the affected hip joint [1-4]. Symptom severity does not always correspond to the degree of damage displayed on the radiograph [7]. Currently, no cure for OA exists and treatments focus on controlling pain and improving function [8]. Physiotherapy is one of these treatments [9]. In the case of lack of response to treatment, total hip arthroplasty (THA) is the surgical procedure of choice, because this treatment improves the patient's quality of life and facilitates the patient's return to activities of daily living (ADLs) and even to labor activities [7,10-12].

Patients who received THA without a rehabilitation program will develop functional limitations within $1 \mathrm{yr}$ after surgery [13-14], and physiotherapy plays an important role in the care of these patients. Physiotherapy can improve strength and gait speed after THA [15] and help prevent frequent complications, which include luxation and thromboembolic disease [16-17]. In addition, physiotherapy increases the patient's mobility and offers education about the exercises and precautions that are necessary during hospitalization and after discharge [89]. Nevertheless, no consensus for the most effective physiotherapy has been reached in the field. Early postoperative protocols with additive interventions or late postoperative programs associated with weight-bearing exercises have been described [18]. Although several reviews have been published, the overall effectiveness of physiotherapy in functional and quality-of-life outcomes remains unclear [15]. The aim of this study was to perform a randomized double-blind trial to determine the effectiveness of a physiotherapeutic in-hospital intervention protocol compared with just the orientation (verbal instructions and exercise demonstrations) of the same protocol to reduce the functional impairment of THA patients over the course of a short follow-up period.

\section{METHODS}

A randomized double-blind trial was performed at the Universidade Federal do Rio Grande do Sul in the Department of Orthopedic Surgery of the Hospital de Clínicas de Porto Alegre. The research was approved by the Hospital Ethics Committee and the Office for Human Research Protections and followed the ethical guidelines of the 1975 Declaration of Helsinki.
The inclusion time was from July 2009 to October 2011. All patients admitted with hip OA and receiving THA surgery were eligible. For this analysis, participants who refused to participate in the study, who lived in another city, who had cognitive disorders that did not allow completion of the questionnaire, and who underwent THA for hip fracture were excluded. All admitted participants were informed about the aim of the study. Before enrollment, participants were informed that one group would receive the assistance already offered to THA patients by the hospital while the other group would receive extra active assistance. The patients were not informed of their assigned group. All patients agreed to participate and provided consent. The study flow diagram is shown in the Figure.

A total of 106 patients participated in this study. Patients were randomly subdivided into the two specific groups. This allocation of participants was blinded to the researcher and to the physiotherapist who assessed and collected the information from participants, and this randomization was conducted by the Hospital Ethics Committee staff. Patients were assigned to this previously selected allocation into the study groups in the order in which they were admitted to the hospital for the arthroplasty surgery. The admission team was also unaware of the order of the randomization process. All patients were evaluated by a blinded physiotherapeutic professional. The THA protocol (THAP) group $(n=52)$ received only the assistance provided by the multidisciplinary hip group, which was comprised of the head nurse and the medical hip staff. This group received introduction and orientation about the rehabilitation protocol without the presence of a physiotherapeutic professional. This assistance was performed once a day for $60 \mathrm{~min}$ and consisted of the following:

- Day 1. Patients received verbal orientation and demonstration of the physiotherapy exercises that would strengthen the gluteal and thigh muscles, as well as a recommendation for three repetitions of 12 complete movements for each exercise. Patients were encouraged to sit outside the bed in a chair to perform these exercises. Movements that should be avoided and the correct positions of the repaired limb were also indicated to these patients.

- Day 2. Patients were provided instructions and demonstrations for gait training.

- Day 3. Patients performed the physiotherapy and gait training exercise until their discharge day. The patients 


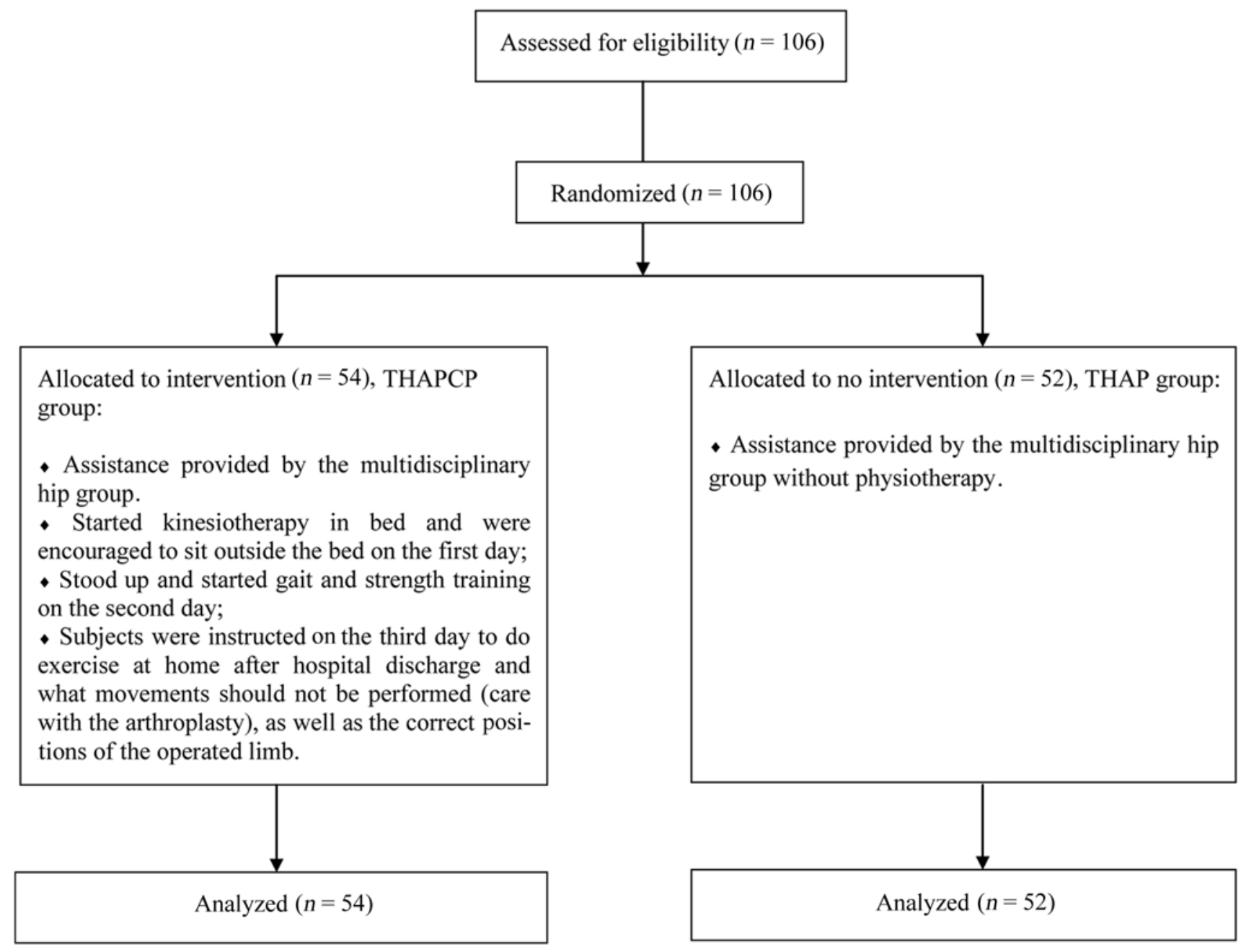

Figure.

Study flow diagram. THAP = total hip arthroplasty protocol, THAPCP = total hip arthroplasty physiotherapy care protocol.

were instructed to continue to perform the physiotherapy exercises at home after hospital discharge and were told what movements should be avoided as well as the correct positions of the surgically repaired limb.

The other group, the THA physiotherapy care protocol (THAPCP) group ( $n=54)$ received the same assistance by the multidisciplinary hip group with the additional presence of a physiotherapy professional. All physiotherapy exercises and gait training were performed with the physiotherapy professional, who was associated with the hip group.

On the 15th postoperative day after discharge during a scheduled outpatient visit, all patients were re-evaluated by the same blinded researcher. The groups were reassessed according to the same parameters measured previously. In addition, the following postoperative outcomes were investigated: functional impairment according to goniometry and muscle strength assessment; discrepancy of the lower limbs; quality of life by the Medical Outcomes Study 36Item Short Form Health Survey (SF-36) [19]; and motor, gait, and pain performances assessed by the Merle d'Aubigné and Postel [20] scores. Goniometry was used to evaluate the range of motion in flexion, extension, adduction, abduction, and internal and external rotation of both hips of the patients [21]. Muscle strength was measured based on Kendall's criteria, and the forces of the muscle groups responsible for flexion, extension, adduction, abduction, internal and external rotation of the hips, and 
flexion and extension of the knees were measured [22]. The muscle strength force scale varies from zero (absence of contraction) to five (normal movement and ability to perform and overcome major resistance). To assess the lower-limb discrepancy, the distance between the umbilicus (proximal reference point) to the medial malleolus of both ankles (distal reference point) was used and reported in centimeters. The Merle d'Aubigné and Postel scores are composed of a clinical performance evaluation and a motor performance evaluation. The clinical evaluation consists of evaluated gait (normal walking), pain (total absence), and mobility (equal to the hip without OA). Each of these items had a maximum score of 6 points, and the maximum score of the clinical performance evaluation was 18 . The motor performance evaluation examined gait and pain, and the total score ranged from 7 (worst) to 12 (best). The SF-36 [19], which was translated and validated for the Portuguese language [23], consisted of 36 items with combined scores ranging from 0 to 100, with 0 indicating the worst outcome and 100 indicating the best outcome.

Database and statistical analyses were performed in SPSS version 18.0 (IBM Corporation; Armonk, New York). A priori sample size was calculated based on a report by Galia [11] and was estimated at 51 participants per group in order to yield a level of significance of 5 percent and a test power of 95 percent. Quantitative variables were described with means, standard deviations, medians, and interquartile ranges (IQRs), and qualitative variables were described by their frequencies. Analysis of variance was used to analyze age differences among groups (sex, race, professional status, THAP, and
THAPCP groups), discrepancy differences in the two randomization groups, and in-hospital stay differences between the sexes and in the two randomization groups. To verify the homogeneous distribution of the groups according to the two randomization groups, Pearson chisquare test was used. To compare preoperative and postoperative results in the same randomized groups and the differences in the postoperative results between the two randomized groups, generalized linear models (GLM) and the Bonferroni test were employed. The muscle strength force scale was ordinal, but insufficient numbers of participants were allocated in all scale groups; therefore, the scores were analyzed according to the Likert scale as a continuous variable, followed by GLM with the Bonferroni test. Differences were considered significant when the two-tailed $p$-value was less than 0.05 .

\section{RESULTS}

All 106 patients enrolled in this study were included in the final analysis. The mean age at the time of hospital admission was $61.4 \pm 15.0$ yr (mean \pm standard deviation) with a range of 27-89 yr (median 64, IQR 49.573.0). No age differences between the randomization groups were detected $(p=0.59)$. The mean in-hospital stay was $5.3 \pm 1.1 \mathrm{~d}$, with a range of $4-7 \mathrm{~d}$ (median 5 , IQR 4.2-6.0), and no differences were observed between the sexes $(p=0.83)$ or between the randomization groups $(p=0.72)$. The descriptive characteristics of this population are displayed in Table 1. The study included more

Table 1.

Population characteristics.

\begin{tabular}{|c|c|c|c|}
\hline \multirow{2}{*}{ Characteristic } & \multicolumn{3}{|c|}{ Group } \\
\hline & All $(n=106)$ & THAP $(n=52)$ & THAPCP $(n=54)$ \\
\hline \multicolumn{4}{|l|}{ Age (yr) } \\
\hline Mean \pm SD & $61.4 \pm 15.0$ & $60.9 \pm 14.5$ & $61.8 \pm 15.6$ \\
\hline Range (IQR) & 27-89 (49.5-73.0) & 27-89 (49.5-72.0) & 27-87 (50.0-73.7) \\
\hline \multicolumn{4}{|l|}{ Sex, $n(\%)$} \\
\hline Male & $49(46.2)$ & $23(44.2)$ & $26(48.1)$ \\
\hline Black & 12 (11.3) & $10(19.2)$ & $2(3.7)$ \\
\hline White & 94 (88.7) & $42(80.8)$ & 52 (96.3) \\
\hline \multicolumn{4}{|l|}{ Profession, $n(\%)$} \\
\hline Working & $52(49.1)$ & $29(55.8)$ & $23(42.6)$ \\
\hline Retired & 54 (50.9) & $23(44.2)$ & 31 (57.4) \\
\hline
\end{tabular}

IQR = interquartile range, SD = standard deviation, THAP = total hip arthroplasty protocol, THAPCP = total hip arthroplasty physiotherapy care protocol. 
women than men, and on average, the women were older than the men, with a mean age of $64.7 \pm 14.5 \mathrm{yr}$ (median 70, IQR 55.0-75.0) for women and $57.5 \pm 14.8 \mathrm{yr}$ (median 59, IQR 44.5-70.0) for men $(p=0.01)$. Sex was equitably distributed between the two groups of our study $(p=0.77)$. The proportion of retirees and active workers was homogeneous in the study and in the randomization groups $(p=0.18)$. Retirees were older, with a mean age of $66.1 \pm 13.8 \mathrm{yr}$ (median 70, IQR 59-75), while active workers had a mean age of $56.5 \pm 14.8$ yr (median 56 , IQR 45-70; $p=0.001$ ). White patients were more prevalent than black patients in this trial, and their distribution in the two experimental groups was significantly different $(p=0.01)$, but no differences in age distribution among races were observed $(p=0.67)$.

Upon evaluation of the preoperative and postoperative goniometry results within groups, the intervention group (THAPCP) had higher outcomes than the nonintervention group (THAP). The THAP group had less change or even insignificant $p$-values for all items measured compared with the THAPCP group. When postoperative results between the two randomized groups were compared, differences in adduction and abduction were noted. These results are displayed in Table 2.
Improvements in the muscle strength force were observed for all movements in both groups (within-group comparison); however, higher scores were noted in the THAPCP group than in the THAP group. Comparison of the postoperative results between these two groups revealed that the intervention (THAPCP) group had significantly greater improvements in muscle strength force in the vast majority of evaluated motions (flexion, extension, adduction, abduction, internal rotation, and external rotation) compared with the nonintervention group (Table 3).

Clinical and motor performance evaluations were assessed with the Merle D'Aubigné and Postel scale (Table 4). The global clinical evaluation of the THAPCP group exhibited a superior and significant improvement compared with that of the THAP group ( $p=0.007$ vs $p=$ 0.10 for within-group improvements; $p<0.001$ for comparison of postoperative improvements between the two groups). In the clinical evaluation, pain showed an improvement in both groups upon comparison of preoperative and postoperative scores (within-group comparison, $p<0.001$ for both groups). In a comparison of final outcomes between groups, the intervention group had higher scores $(p=0.02)$ for pain than the nonintervention group.

Table 2.

Results of comparison assessing goniometry.

\begin{tabular}{|c|c|c|c|c|}
\hline Movement & Preoperative (Mean \pm SE) & Postoperative (Mean \pm SE) & $p$-Value ${ }^{*}$ & $p$-Value ${ }^{\dagger}$ \\
\hline$\overline{\text { Flexion }\left(^{\circ}\right)}$ & & & & 0.43 \\
\hline THAP & $64.3 \pm 2.3$ & $67.3 \pm 2.2$ & 0.15 & \\
\hline Extension $\left({ }^{\circ}\right)$ & & & & $>0.99$ \\
\hline THAP & $20.6 \pm 2.7$ & $24.3 \pm 3.1$ & 0.001 & \\
\hline THAPCP & $19.2 \pm 1.2$ & $25.1 \pm 1.2$ & $<0.001$ & \\
\hline THAP & $18.5 \pm 1.1$ & $21.1 \pm 1.1$ & $<0.001$ & \\
\hline THAPCP & $23.7 \pm 1.5$ & $27.2 \pm 1.3$ & $<0.001$ & \\
\hline Abduction $\left(^{\circ}\right)$ & & & & 0.01 \\
\hline THAP & $23.8 \pm 1.4$ & $25.7 \pm 1.3$ & 0.08 & \\
\hline THAPCP & $27.7 \pm 1.3$ & $31.7 \pm 1.4$ & $<0.001$ & \\
\hline THAP & $16.6 \pm 1.0$ & $17.8 \pm 0.8$ & 0.07 & \\
\hline THAPCP & $17.2 \pm 1.1$ & $21.1 \pm 1.2$ & $<0.001$ & \\
\hline
\end{tabular}


JRRD, Volume 51, Number 10, 2014

Table 3.

Results of comparison assessing muscle strength.

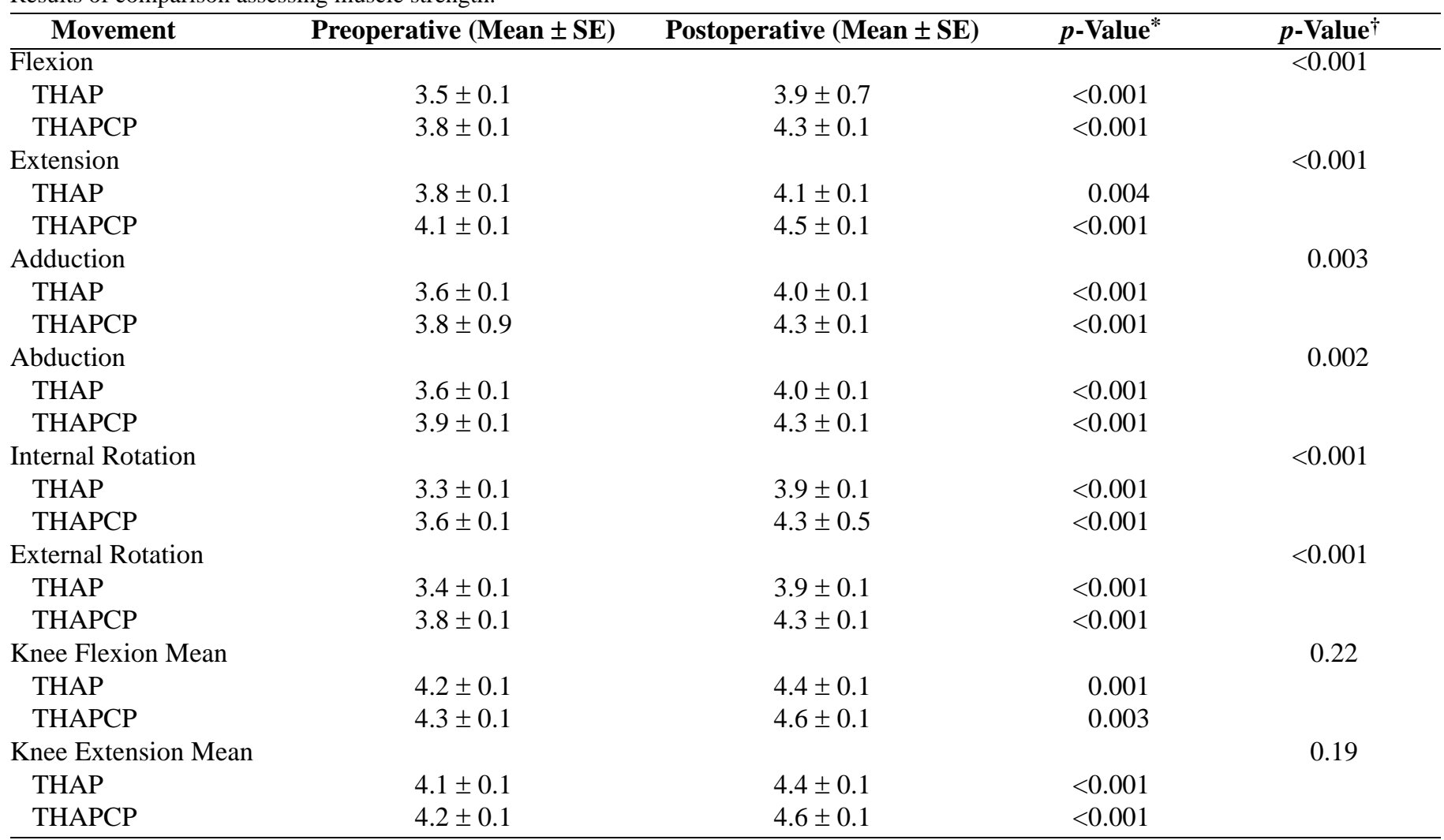

${ }^{*}$ Bonferroni test comparison preoperative and postoperative in same randomized group.

${ }^{\dagger}$ Bonferroni test comparison postoperative results between randomized groups.

$\underline{\mathrm{SE}}=$ standard error, THAP = total hip arthroplasty protocol, THAPCP = total hip arthroplasty physiotherapy care protocol.

Table 4.

Results of clinical and motor evaluation by Merle d'Aubigné and Postel score.

\begin{tabular}{|c|c|c|c|c|}
\hline Variable Evaluated & Preoperative (Mean \pm SE) & Postoperative (Mean \pm SE) & $p$-Value* & $p$-Value ${ }^{\dagger}$ \\
\hline Motor Performance Evaluation & & & & 0.47 \\
\hline THAP & $8.7 \pm 0.1$ & $8.3 \pm 0.1$ & 0.16 & \\
\hline THAPCP & $9.2 \pm 0.1$ & $8.6 \pm 0.1$ & 0.03 & \\
\hline Pain Clinical Evaluation & & & & 0.02 \\
\hline THAP & $1.7 \pm 0.2$ & $3.4 \pm 0.1$ & $<0.001$ & \\
\hline THAP & $3.3 \pm 0.1$ & $3.5 \pm 0.1$ & 0.08 & \\
\hline THAPCP & $3.6 \pm 0.1$ & $4.1 \pm 0.1$ & $<0.001$ & \\
\hline Gait Clinical Evaluation & & & & 0.34 \\
\hline THAP & $2.6 \pm 0.2$ & $1.6 \pm 0.1$ & 0.004 & \\
\hline THAPCP & $2.9 \pm 0.2$ & $2.2 \pm 0.2$ & 0.17 & \\
\hline
\end{tabular}


Improvement in the mobility score was noted only in the intervention group (THAPCP). The motor performance evaluation revealed higher results for the THAPCP group (pre- to postoperative comparison within group); however, taking only the postoperative assessment into account, no differences in the final results comparison were found between the two groups.

According to the results of the scores of the SF-36, both trial groups showed less improvement in the areas of physical functioning, role physical, and role emotional (within-group comparison; Table 5). Improvements were observed in both groups for all other items in withingroup comparisons, whereas higher scores were noted for the THAPCP group. Bodily pain was the only issue that exhibited significant improvement in the comparison between the groups ( $p=0.01)$.

Regarding the discrepancy and the length in the lower limbs, the 106 patients had an average length of $90.4 \pm$ $0.6 \mathrm{~cm}$ in the limb with OA/THA and $91.1 \pm 0.6 \mathrm{~cm}$ in the limb without THA. The preoperative discrepancies, which were defined as the length of the nonoperated leg minus the length of the leg with OA/THA, were $1.9 \pm 1.2 \mathrm{~cm}$ (median 2, IQR 1-3) for the THAP group and $1.9 \pm 2.0 \mathrm{~cm}$ (median 1, IQR 1-2) for the THAPCP group (preoperative comparison between groups, $p=0.90$ ). Postoperatively, these differences were $0.6 \pm 1.2 \mathrm{~cm}$ (median 0 , IQR $0-1$ ) for the THACP group and $0.7 \pm 1.4 \mathrm{~cm}$ (median 0 , IQR $0-1$ ) for the THAPCP group (postoperative comparison between groups, $p=0.74$ ).

\section{DISCUSSION}

Concern about patient rehabilitation and high hospital costs has motivated many hospitals to create and/or upgrade their rehabilitation protocols to reduce the length of the hospital stay without affecting the outcome of the

Table 5.

Outcome of subitems on Medical Outcomes Study 36-Item Short Form Health Survey.

\begin{tabular}{|c|c|c|c|c|}
\hline Subitem & Preoperative (Mean \pm SE) & Postoperative (Mean \pm SE) & $p$-Value* & $p$-Value ${ }^{\dagger}$ \\
\hline Physical Functioning & & & & $>0.99$ \\
\hline THAP & $9.9 \pm 2.5$ & $12.7 \pm 2.5$ & $>0.99$ & \\
\hline THAPCP & $13.8 \pm 2.5$ & $13.5 \pm 2.5$ & $>0.99$ & \\
\hline Role Physical & & & & $>0.99$ \\
\hline THAP & $12.7 \pm 4.0$ & $9.6 \pm 4.0$ & $>0.99$ & \\
\hline THAPCP & $11.8 \pm 4.0$ & $11.1 \pm 3.9$ & $>0.99$ & \\
\hline Bodily Pain & & & & 0.01 \\
\hline THAP & $26.1 \pm 2.2$ & $43.9 \pm 2.2$ & $<0.001$ & \\
\hline THAPCP & $29.2 \pm 2.2$ & $53.8 \pm 2.2$ & $<0.001$ & \\
\hline General Health & & & & 0.86 \\
\hline THAP & $71.3 \pm 2.2$ & $79.02 \pm 2.2$ & 0.09 & \\
\hline THAPCP & $70.4 \pm 2.1$ & $83.5 \pm 2.1$ & $<0.001$ & \\
\hline Vitality & & & & 0.27 \\
\hline THAP & $52.6 \pm 2.6$ & $66.5 \pm 2.6$ & $<0.001$ & \\
\hline THAPCP & $52.9 \pm 2.6$ & $74.1 \pm 2.6$ & $<0.001$ & \\
\hline Social Functioning & & & & 0.19 \\
\hline THAP & $39.1 \pm 3.1$ & $52.8 \pm 3.1$ & 0.01 & \\
\hline THAPCP & $45.6 \pm 3.1$ & $62.2 \pm 3.1$ & 0.001 & \\
\hline Role Emotional & & & & $>0.99$ \\
\hline THAP & $24.3 \pm 5.9$ & $28.8 \pm 5.9$ & $>0.99$ & \\
\hline THAPCP & $32.7 \pm 5.8$ & $40.1 \pm 5.8$ & $>0.99$ & \\
\hline Mental Health & & & & 0.08 \\
\hline THACP & $54.7 \pm 2.6$ & $67.7 \pm 2.63$ & 0.003 & \\
\hline ТНAРСР & $63.9 \pm 2.5$ & $76.9 \pm 2.58$ & 0.002 & \\
\hline
\end{tabular}


surgical treatment employed. These measures would thereby provide greater safety and patient satisfaction. As a result, the physiotherapeutic rehabilitation protocol was created in an attempt to improve the efficiency of the assistance provided by the multidisciplinary hip group protocol to patients receiving THA surgery. This protocol, which was developed by Galia [11], was implemented by our hospital, and we expected that patients would exhibit better functional outcomes $15 \mathrm{~d}$ after THA surgery. According to Viliani et al. [24], the main aspects that should be addressed in rehabilitation protocols are attention to and caution with the posture and the position of the operated limb, thromboembolic disease prevention, return of mobility, and patient education for taking care of the prosthesis after hospital discharge. Rehabilitation success and the reduction in length of hospital stay should also take into account an exercise program with daily mobilization, physiotherapy, and gait training during hospitalization $[11,25]$. Our study adhered to these principles, and all patients in the intervention group were discharged without related complications and in good clinical and functional condition as expected. No statistical differences, however, were observed between the randomization groups with regard to the length of hospitalization. Therefore, it is assumed that there was no reduction in costs related to the difference in length of hospital stay between the randomized groups due to implementation of the rehabilitation protocol.

The results of this randomized trial revealed that the physiotherapeutic in-hospital intervention (physiotherapy and gait training) in conjunction with information about arthroplasty care (movements that should not be performed) and home exercises was effective in improving muscle strength force, range of motion, and the mobility and pain scores in the Merle D’Aubigné and Postel scale over a short follow-up period. The decision to examine a short follow-up period resulted from our conclusion that no previous study has shown the efficacy of a rehabilitation protocol in a very short follow-up period of $15 \mathrm{~d}$ postsurgery. Most of the previous studies [13,26-28] made assessments over periods of 4, 8, 12, and $16 \mathrm{wk}$.

In a meta-analysis by Ewen et al. [29], the flexion and extension range of motion was reduced, with a range of $31.2^{\circ}-51.0^{\circ}$ in the control group and $23.1^{\circ}-40.7^{\circ}$ in the intervention group. Our study demonstrated that the flexion and extension movements were $67.3^{\circ}$ and $24.3^{\circ}$, respectively, in the control group and $73.0^{\circ}$ and $25.1^{\circ}$, respectively, in the intervention group. Better outcomes were obtained for hip flexion, and worse but statistically significant outcomes were obtained for hip extension. Based on a report by Hodge et al. [30], Ewen et al. suggested that these findings in combination with a significant reduction in the hip range of motion may be associated with a reduction in the various hip stem positions [29]. This hypothesis can be neither supported nor refuted with evidence from this study, however, because our study did not evaluate the stem position. Nevertheless, the goniometry assessment made during this study revealed that the results for the THAPCP group were higher than for the THAP group, and these data support the use of physiotherapy according to Viliani et al. [24].

Muscle strength declines 3-4 percent each day during the first week of immobilization [31], and patients who receive THA commonly experience a period of inactivity ahead of surgery [32], possibly due to the presence of pain [33]. This negative effect on muscle mass has been reported previously [31,34]. Adequate muscle strength in the lower limbs, primarily in the abductor muscle, is required for satisfactory rehabilitation [35]. Initiation of strength training as soon as possible after surgery is of great importance to decrease the influence of postsurgery immobilization on the impairment of muscle mass [36], as recommended by the present study. The current study demonstrated significant positive results in the improvement of muscle strength force in the intervention group compared with the nonintervention group, and these findings were similarly highlighted by Husby et al. [33] in another randomized study. Even with good outcomes in the muscle strength force as measured by Kendall's criteria [22], this method may be imprecise when compared with a previously described method using a dynamometer, an instrument that is thought to have higher measurement accuracy [26,28,37]. Kendall's criteria [22] can be incorrect due to the negative influence of the patient's pain as well as due to measurements obtained by different researchers. Similarly, these factors can also influence measurement when using a dynamometer. In a systematic review, Minns Lowe et al. indicated a lack of a standard method among researchers for the measurement of muscle strength [38]. In fact, some authors use manual measurement [39-40], while others use a dynamometer [26,28,37]. Even those who use a dynamometer often measure the strength of different muscle groups. Regardless of the method used to measure the muscle strength force, we demonstrated a significant improvement after a short follow-up time in the intervention group compared with the nonintervention group. This finding 
strengthens our conclusions that our protocol leads to a clinically relevant improvement in muscle strength in a short period of time and that this improvement is essential for fast patient recovery.

The lack of available trials concerning the functional evaluation of patients after THA indicates the absence of a consensus among authors regarding the best way to evaluate functional status [38]. A variety of tools has been described: the Oxford Hip score [13], The McMaster Toronto Arthritis Patient Preference Disability Questionnaire [41], and the Japanese Orthopedic Score [40]. The SF-36 [19] and the Merle d'Aubigné and Postel [20] score are other examples of validated scores [10]. All these scores can determine the functional capacity of patients with a degenerative hip and can provide a useful quantification of the disease extension. These tools may provide an indication for a certain surgical procedure as well as evaluate the results of the procedure. The Merle d'Aubigné and Postel and SF-36 scores were chosen for this study. Mehta et al. [42] evaluated 1,700 THA surgeries in 1,560 patients and found that pain and the general health status of these patients were significantly correlated with validated hip scores and general health questionnaires, such as the Merle d'Aubigné and Postel [20] and the SF-36 [19] scores. Galia [11] evaluated the functional results of a multidisciplinary hip group intervention in patients receiving THA by using application of the Merle d'Aubigné and Postel [20] score. In the Galia study [11], positive outcomes were associated with high scores on the Merle d'Aubigné and Postel [20] index. Similar results were obtained for most aspects assessed in the current randomized trial. Significant improvements were found in comparisons of the two groups for pain, mobility, and clinical evaluation. Even without differences between groups in the other areas, the intervention group showed significant improvement and higher values in within-group comparisons in the following areas: general health, vitality, social functioning, and mental health. These findings confirm that the Merle d'Aubigné and Postel [20] and the SF-36 [19] scores are effective and reliable and indicate that the proposed interventions result in a clinical application with improvement in most of the issues assessed.

Several enhanced recovery programs for THA are currently under discussion [43-44]. One of the goals of these programs is to decrease the length of hospitalization. Malviya et al. showed that mean overall hospitalization time decreased from $8.5 \mathrm{~d}$ (conventional care) to $4.8 \mathrm{~d}$ (enhanced program) [43], and Dwyer et al. demonstrated a reduction in hospital stay from 8.3 to $5.3 \mathrm{~d}$ following implementation of the program [44]. These authors documented a real improvement with the enhanced program. In this study, the overall mean hospitalization time was similar to that of the enhanced groups from these studies. The major outcome of the intervention in this study was in muscle strength force and range of motion rehabilitation. The question of whether improvements in the length of hospitalization decrease muscle strengthening and range of motion gain remains. These previous studies did not evaluate these issues.

This study has several strengths. First, this study is a randomized clinical trial that was conducted in southern Brazil in order to evaluate the applicability and the functional results of a physiotherapy care protocol for THA surgical patients. Not only the functional status according to goniometry and muscle strength force assessment, but also the clinical status and quality of life assessment according to the SF-36 [19] and the Merle d'Aubigné and Postel [20] scales were determined. Moreover, an attentive randomization process was performed before the beginning of the study and a blinding process that minimized bias was employed. The current study also has some limitations due to the nature of the data collection method. Patient comorbidities were not included, and the gait evaluation was reported as the measurement of speed. Both of these factors may have influenced the final status evaluation. Despite the fact that this was a single-center study, the population is highly representative of our region because the center is the reference center for 4 million people.

\section{CONCLUSIONS}

The developed physiotherapy rehabilitation protocol implemented in routine care by the hip multidisciplinary care group yielded functional improvement in patients receiving THA. Results of this study indicate that this intervention provided pain relief, promoted rehabilitation and the reintegration of patients into ADLs (evaluated by social functioning aspects, vitality, general health, and mental health status), and provided a better quality of life through the patients' reintegration into social life [11,45]. The results obtained in this study also demonstrated that the intervention protocol improved functional capacity over a short period of time and improved the quality of 
life in the vast majority of assessed aspects. In conclusion, these findings confirm that this physiotherapeutic protocol intervention is a safe tool for accelerating recovery after THA surgery when compared with instructions and demonstrations. Our study emphasizes that the action of a physiotherapist is of great importance for the successful rehabilitation of the patient after THA surgery.

\section{ACKNOWLEDGMENTS}

\section{Author Contributions:}

Study concept and design: C. S. Umpierres, T. A. Ribeiro, C. R. Galia, C. A. S. Macedo.

Acquisition of data: C. S. Umpierres, Â. E. Marchisio, L. Galvão, Í. N. K. Borges.

Analysis of data: C. S. Umpierres, T. A. Ribeiro.

Interpretation of data: C. S. Umpierres, T. A. Ribeiro, Â. E. Marchisio, L. Galvão, Í. N. K. Borges, C. R. Galia.

Drafting of manuscript: C. S. Umpierres, T. A. Ribeiro, Â. E. Marchisio, L. Galvão, Í. N. K. Borges, C. A. S. Macedo, C. R. Galia.

Financial Disclosures: The authors have declared that no competing interests exist.

Funding/Support: This material was unfunded at the time of manuscript preparation.

Institutional Review: The research was approved by the Hospital Ethics Committee and by the Office for Human Research Protections and followed the ethical guidelines of the 1975 Declaration of Helsinki. All patients agreed to participate and provided consent.

Participant Follow-Up: The authors do not plan to inform participants of the publication of this study.

\section{REFERENCES}

1. Flugsrud GB, Nordsletten L, Reinholt FP, Risberg MA, Rydevik K, Uhlig T. [Osteoarthritis]. Tidsskrift for den Norske laegeforening: tidsskrift for praktisk medicin, ny raekke. Christiania og Kjobenhavn: Alb. Cammermeyers Forlag. 2010;130(21):2136-40. Norwegian.

2. Patrizzi LJ, Vilaça KH, Takata ET, Trigueiro G. Análise pré e pós-operatória da capacidade funcional e qualidade de vida de pacientes portadores de Osteoartrose de quadril submetidos à Artroplastia Total. Revista Brasileira de Reumatologia. 2004;44:185-91. Portuguese.

3. IBGE. Pesquisa Nacional por Amostra de Domicílios 2009 [Internet]. Rio de Janeiro (Brazil): Instituto Brasileiro de Geografia e Estatística; 2009 [cited 2009 Feb 25]. Available from: http://www.ibge.gov.br/home/estatistica/populacao/ trabalhoerendimento/pnad2009/default.shtm

4. Sharma L, Kapoor D, Issa S. Epidemiology of osteoarthritis: An update. Curr Opin Rheumatol. 2006;18(2):147-56.

\section{[PMID:16462520]}

http://dx.doi.org/10.1097/01.bor.0000209426.84775.f8

5. Alviar MJ, Olver J, Brand C, Hale T, Khan F. Do patientreported outcome measures used in assessing outcomes in rehabilitation after hip and knee arthroplasty capture issues relevant to patients? Results of a systematic review and ICF linking process. J Rehabil Med. 2011;43(5):374-81. [PMID:21448553] http://dx.doi.org/10.2340/16501977-0801

6. Zavadak KH, Gibson KR, Whitley DM, Britz P, Kwoh CK. Variability in the attainment of functional milestones during the acute care admission after total joint replacement. J Rheumatol. 1995;22(3):482-87. [PMID:7783066]

7. Trigueiro G. Estudo clínico e radiográfico do fêmur nas artroplastias totais do quadril com a haste não cimentada de Spotorno. São Paulo (Brazil): Universidade Federal de São Paulo; 1997. Portuguese.

8. Nicolaides AN, Fernandes e Fernandes J, Pollock AV. Intermittent sequential pneumatic compression of the legs in the prevention of venous stasis and postoperative deep venous thrombosis. Surgery. 1980;87(1):69-76. [PMID:6985760]

9. Caiafa JS. Medidas profiláticas da doença tromboembólica. In: Thomás JB, editor. Síndromes venosas: diagnóstico e tratamento. Rio de Janeiro (Brazil): Revinter; 2001. Portuguese.

10. Freburger JK. An analysis of the relationship between the utilization of physical therapy services and outcomes of care for patients after total hip arthroplasty. Phys Ther. 2000;80(5):448-58. [PMID:10792855]

11. Galia CR. Avaliação preliminar de um protocolo assistencial de artroplastia total de quadril. Rev Fac Méd Córdoba. 2002;59(1):101-7. Portuguese.

12. Bergqvist D, Hull RD. Effective thromboprophytaxis administered close to the time of major orthopedic surgery: A review. Am J Orthop. 2006;35(5):226-30. [PMID:16764181]

13. Trudelle-Jackson E, Smith SS. Effects of a late-phase exercise program after total hip arthroplasty: A randomized controlled trial. Arch Phys Med Rehabil. 2004;85(7):1056-62. [PMID:15241750] http://dx.doi.org/10.1016/j.apmr.2003.11.022

14. Okoro T, Lemmey AB, Maddison P, Andrew JG. An appraisal of rehabilitation regimes used for improving functional outcome after total hip replacement surgery. SMARTT. 2012;4(1):5. [PMID:22313723]

http://dx.doi.org/10.1186/1758-2555-4-5

15. Coulter CL, Scarvell JM, Neeman TM, Smith PN. Physiotherapist-directed rehabilitation exercises in the outpatient or home setting improve strength, gait speed and cadence after elective total hip replacement: A systematic review. J Physiother. 2013;59(4):219-26. [PMID:24287215] http://dx.doi.org/10.1016/S1836-9553(13)70198-X 
16. Hagemeyer V, Buksman S, Vilela AL. Profilaxia do tromboembolismo venoso em cirurgias ortopédicas de idosos. $\mathrm{R}$ Into. 2004;Maio/Agosto:1-60. Portuguese.

17. Ribeiro KS. A atuação da fisioterapia na atenção primária à saúde. Fisioterapia Brasil. 2002;3(5):311-18. Portuguese.

18. Di Monaco M, Vallero F, Tappero R, Cavanna A. Rehabilitation after total hip arthroplasty: A systematic review of controlled trials on physical exercise programs. Eur J Phys Rehabil Med. 2009;45(3):303-17. [PMID:19238130]

19. Ware JE Jr, Sherbourne CD. The MOS 36-item short-form health survey (SF-36). I. Conceptual framework and item selection. Med Care. 1992;30(6):473-83. [PMID:1593914] http://dx.doi.org/10.1097/00005650-199206000-00002

20. d'Aubigné RM, Postel M. The classic: Functional results of hip arthroplasty with acrylic prosthesis. 1954. Clin Orthop Relat Res. 2009;467(1):7-27. [PMID:18941852] http://dx.doi.org/10.1007/s11999-008-0572-1

21. Marques AP. Manual de goniometria. 2nd ed. São Paulo (Brazil): Manole; 2003. Portuguese.

22. Miller DW, Hahn JF. General methods of clinical examination. In: Youmans JR, editor. Neurological surgery. 4th ed. Philadelphia (PA): W. B. Saunders Company; 1996. p. 31-32.

23. Ciconelli RM. Tradução para o português e validação do Questionário Genérico de Avaliação de Qualidade de Vida "Medical Outcomes Study 36-item Short-Form Health Survey (SF-36)” [dissertation]. [São Paulo, Brazil]: Universidade Federal de São Paulo; 1997. Portuguese.

24. Viliani T, Huber U, Pasquetti P, Poli P, Marcucci M, Popolizio A. Rehabilitation after primary total hip replacement. Comparison between Italian and international protocols. Eura Medicophys. 2004;40(2):67-74. [PMID:16046929]

25. Siggeirsdottir K, Olafsson O, Jonsson H, Iwarsson S, Gudnason V, Jonsson BY. Short hospital stay augmented with education and home-based rehabilitation improves function and quality of life after hip replacement: Randomized study of 50 patients with 6 months of follow-up. Acta Orthop. 2005;76(4):555-62. [PMID:16195074] http://dx.doi.org/10.1080/17453670510041565

26. Jan MH, Hung JY, Lin JC, Wang SF, Liu TK, Tang PF. Effects of a home program on strength, walking speed, and function after total hip replacement. Arch Phys Med Rehabil. 2004;85(12):1943-51. [PMID:15605331] http://dx.doi.org/10.1016/j.apmr.2004.02.011

27. Patterson AJ, Murphy NM, Nugent AM, Finlay OE, Nicholls DP, Boreham CA, Steele I, Henderson SA, Beringer TR. The effect of minimal exercise on fitness in elderly women after hip surgery. Ulster Med J. 1995;64(2):118-25. [PMID:8533175]

28. Suetta C, Aagaard P, Rosted A, Jakobsen AK, Duus B, Kjaer M, Magnusson SP. Training-induced changes in muscle CSA, muscle strength, EMG, and rate of force development in elderly subjects after long-term unilateral disuse. J
Appl Physiol. 2004;97(5):1954-61. [PMID:15247162]

http://dx.doi.org/10.1152/japplphysiol.01307.2003

29. Ewen AM, Stewart S, St Clair Gibson A, Kashyap SN, Caplan N. Post-operative gait analysis in total hip replacement patients - a review of current literature and meta-analysis. Gait Posture. 2012;36(1):1-6. [PMID:22410129] http://dx.doi.org/10.1016/j.gaitpost.2011.12.024

30. Hodge WA, Andriacchi TP, Galante JO. A relationship between stem orientation and function following total hip arthroplasty. J Arthroplasty. 1991;6(3):229-35.

[PMID:1940928]

http://dx.doi.org/10.1016/S0883-5403(06)80169-5

31. Appell HJ. Muscular atrophy following immobilisation. A review. Sports Med. 1990;10(1):42-58. [PMID:2197699] http://dx.doi.org/10.2165/00007256-199010010-00005

32. Husby VS, Helgerud J, Bjørgen S, Husby OS, Benum P, Hoff J. Early postoperative maximal strength training improves work efficiency 6-12 months after osteoarthritis-induced total hip arthroplasty in patients younger than 60 years. Am J Phys Med Rehabil. 2010;89(4):304-14. [PMID:20134307] http://dx.doi.org/10.1097/PHM.0b013e3181cf5623

33. Husby VS, Helgerud J, Bjørgen S, Husby OS, Benum P, Hoff J. Early maximal strength training is an efficient treatment for patients operated with total hip arthroplasty. Arch Phys Med Rehabil. 2009;90(10):1658-67.

[PMID:19801053]

http://dx.doi.org/10.1016/j.apmr.2009.04.018

34. Gruther W, Benesch T, Zorn C, Paternostro-Sluga T, Quittan M, Fialka-Moser V, Spiss C, Kainberger F, Crevenna R. Muscle wasting in intensive care patients: Ultrasound observation of the M. quadriceps femoris muscle layer. J Rehabil Med. 2008;40(3):185-89. [PMID:18292919]

http://dx.doi.org/10.2340/16501977-0139

35. Johnstone JJ, Noble PC, Hurwitz DE, Andriacchi TP. Biomechanics of the hip. In: Callaghan JJ, Rosenberg A, Rubash HE, editors. The adult hip. 2nd ed. Philadelphia (PA): Lippincott, Williams \& Wilkins; 2007. p. 81-90.

36. Suetta C, Magnusson SP, Rosted A, Aagaard P, Jakobsen AK, Larsen LH, Duus B, Kjaer M. Resistance training in the early postoperative phase reduces hospitalization and leads to muscle hypertrophy in elderly hip surgery patients - a controlled, randomized study. J Am Geriatr Soc. 2004;52(12):2016-22. [PMID:15571536] http://dx.doi.org/10.1111/j.1532-5415.2004.52557.x

37. Johnsson R, Melander A, Onnerfält R. Physiotherapy after total hip replacement for primary arthrosis. Scand J Rehabil Med. 1988;20(1):43-45. [PMID:3413454]

38. Minns Lowe CJ, Barker KL, Dewey ME, Sackley CM. Effectiveness of physiotherapy exercise following hip arthroplasty for osteoarthritis: A systematic review of clinical trials. BMC Musculoskelet Disord. 2009;10:98. [PMID:19653883] http://dx.doi.org/10.1186/1471-2474-10-98 
39. Kaae K, Kristianson B, Clausen L. Hofteprojeckt [Hip project]. Danske Fysioterapeuten. 1989;3:4-9. Danish.

40. Sashika H, Matsuba Y, Watanabe Y. Home program of physical therapy: Effect on disabilities of patients with total hip arthroplasty. Arch Phys Med Rehabil. 1996;77(3):273-77. [PMID:8600871] http://dx.doi.org/10.1016/S0003-9993(96)90111-2

41. Nyberg B, Kreuter M. Sjukgymnastick gruppträning jämfört med hemträning för patienter opererade med total höftledsplastik [Physiotherapist-led group training compared to home training for patients receiving total hip replacements]. Nordisk Fysioterapi. 2002;6:82-88. Norwegian.

42. Mehta JS, Kiryluk S, Fordyce MJ. Pain and satisfaction after hip replacement: The patient's perspective at 5-12 years. Hip Int. 2005;2(15):112-18.

43. Malviya A, Martin K, Harper I, Muller SD, Emmerson KP, Partington PF, Reed MR. Enhanced recovery program for hip and knee replacement reduces death rate. Acta Orthop. 2011;82(5):577-81. [PMID:21895500] http://dx.doi.org/10.3109/17453674.2011.618911

44. Dwyer AJ, Tarassoli P, Thomas W, Porter P. Enhanced recovery program in total hip arthroplasty. Indian J Orthop. 2012;46(4):407-12. [PMID:22912515] http://dx.doi.org/10.4103/0019-5413.98829

45. Healy WL, Ayers ME, Iorio R, Patch DA, Appleby D, Pfeifer BA. Impact of a clinical pathway and implant standardization on total hip arthroplasty: A clinical and economic study of short-term patient outcome. J Arthroplasty. 1998;13(3): 266-76. [PMID:9590637] http://dx.doi.org/10.1016/S0883-5403(98)90171-1

Submitted for publication May 25, 2014. Accepted in revised form October 13, 2014.

This article and any supplementary material should be cited as follows:

Umpierres CS, Ribeiro TA, Marchisio ÂE, Galvão L, Borges ÍN, Macedo CA, Galia CR. Rehabilitation following total hip arthroplasty evaluation over short follow-up time: Randomized clinical trial. J Rehabil Res Dev. 2014; 51(10):1567-78.

http://dx.doi.org/10.1682/JRRD.2014.05.0132

ResearcherID/ORCID: Tiango Aguiar Ribeiro, PhD: E5674-2013; Carlos Roberto Galia, PhD: N-3717-2014

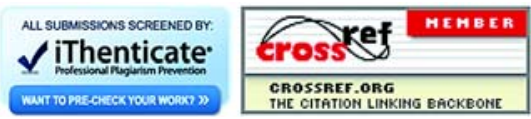

